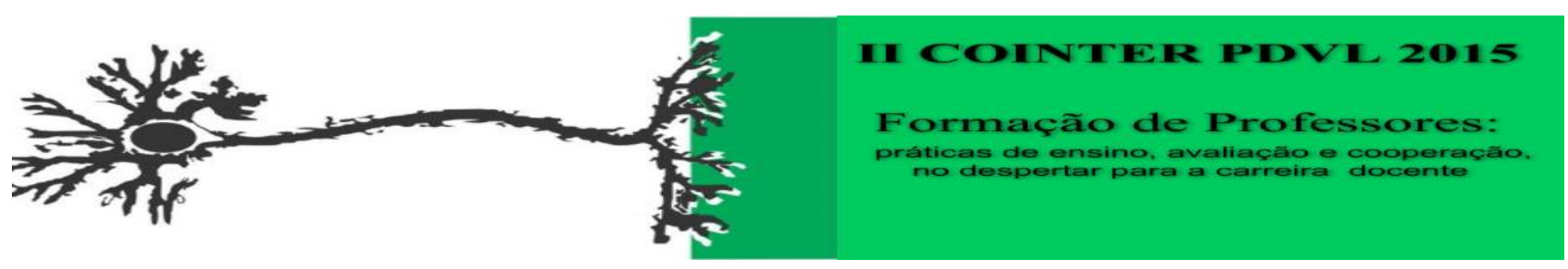

\title{
FEIRA AGROPECUARIA COMO FERRAMENTA DIDÁTICA: CONTEXTUALIZAÇÃO E EXPERIMENTAÇÃO NO ENSINO DE QUÍMICA
}

Apresentação: Pôster

\begin{abstract}
Vânia Costa Ferreira Vanuchi ${ }^{1}$; Andrômeda Serpa Hermano de Souza ${ }^{2}$; José Antônio Avelar
\end{abstract} Baptista $^{3}$; Renato André Zan. ${ }^{4}$

\section{Introdução}

A disciplina de Química compõe a Base Nacional Comum das matrizes curriculares dos estabelecimentos que ofertam Ensino Médio, geralmente é inserida na vida do aluno, somente na adolescência e o acompanha por todo ensino médio (RIBEIRO et, al.2014).

A Química é rotulada pela a maioria dos alunos como uma disciplina complexa e de difícil compreensão. Desta situação resulta um grande desinteresse e até uma rejeição pela Química, por parte da maioria dos alunos (KRÜGER, 1990).Apresentar aos alunos diferentes formas de promover a aprendizagem é mostrar que a química esta em seu cotidiano. Assim o professor pode usar desse meio para aproximar aluno e conteúdo. Buscar novas metodologias é melhorar o elo entre conhecimento e aprendizagem (VANUCHI et, al.2014).Diante das afirmações anteriores, fica evidente que no ensino de ciências, a experimentação pode ser uma estratégia eficiente para demonstrar os conteúdos trabalhados e para resolução de problemas reais que permite um ensino contextualizado (SILVA, 2014).

Neste contexto surge a possibilidade da exposição dos conceitos químicos nas feiras agropecuárias, sendo em questão a EXPOJIPA, Exposição Agropecuária de Ji-Paraná - RO, evento do agronegócio da região, onde existe a exposição de animais, produções industriais e do agronegócio, eventos culturais e de entretenimentos. A EXPOJIPA acontece anualmente no mês de Julho de cada ano, recebe um publico estimado de 300 mil pessoas, sendo este bem diversificado. Está feira encontra-se em sua $36^{\text {a }}$ edição e que ultimamente tem aberto espaço para atividades na área da educação, onde foi introduzida a ideia de exposição de experimentos na área de química.

\footnotetext{
${ }^{1}$ Graduanda em Licenciatura em Química, Instituto Federal de Rondônia - IFRO, vaniakeel@hotmail.com

${ }^{2}$ Graduanda em Licenciatura em Química, Instituto Federal de Rondônia - IFRO, serpa_shs266@hotmail.com

${ }^{3}$ Dr. Em Química, Prof. EBTT em Química, , Instituto Federal de Rondônia - IFRO, jose.antonio@ifro.edu.br

${ }^{4}$ Doutorando em Química de Produtos Naturais IPPN-UFRJ, Prof. EBTT em Química, Instituto Federal de Rondônia IFRO, renato-zan@hotmail.com
} 
Assim esse trabalho justifica-se pela importância, de diversificar o ensino, uma vez que as escolas fazem visitação na feira, no período diurno e no noturno. Bem como uma diversidade de pessoas, tais como crianças, adultos e idosos, de níveis escolares bem diversificados, como também, pela importância da contextualização para o ensino de química usando a experimentação para fazer essa intermediação.

\section{Fundamentação Teórica}

Para Veiga, Quenenhenn e Cargnin (2012), os currículos ressaltam que o ensino de química não pode se resumir apenas à transmissão de conhecimento, mas sim, que este ensino faça referência com a vida do aluno, para que o mesmo possa assimilá-lo com mais facilidade, porém, considerando que o processo ensino aprendizagem acontece mediante reflexões, o ponto de partida para ensinar uma disciplina acontece por meio de fundamentação teórica, como também do saber pedagógico do professor e sua capacidade em conduzir sua aula.

De acordo com Forte (2006), o professor é responsável em lançar mão de instrumentos alternativos para alcançar seus alunos de forma significativa. Isto significa trazer para o educando novas informações, levando em conta seus saberes anteriores e envolver o aluno de tal forma que este consiga correlacionar e assimilar novos conceitos com os velhos (GUIMARÃES, 2009).

A aprendizagem para ser significativa deve favorecer a aptidão natural da mente em formular e resolver problemas essenciais e, de modo correlato, estimular o uso total da inteligência (MORIN, 2003).Segundo Guimarães 2009, nessa perspectiva, o conteúdo a ser trabalhado caracteriza-se como resposta aos questionamentos feitos pelos educando durante a interação com o contexto criado. Quando o experimento é realizado com a intenção de que os alunos obtenham os resultados esperados pelo professor, não há problema algum a ser resolvido, e o aprendiz não é desafiado a testar suas próprias hipóteses ou encontrar inconsistência entre sua forma de explicar e a aceita cientificamente.

A experimentação no ensino de ciência não irá em nenhum momento substituir a aula teórica, mais devido a difícil aceitação e as dificuldades enfrentadas pelos alunos, quanto a disciplina de Química é evidente que uma nova metodologia ,no caso a experimentação aliada a um novo ambiente de aprendizagem, possibilitaria o ensino-aprendizagem.

Para Moreira 2007, o ambiente de aprendizagem escolar é um lugar previamente organizado para promover oportunidades de aprendizagem e que se constitui de forma única na medida em que é socialmente construído por alunos e professores a partir das interações que estabelecem entre si e com as demais fontes materiais e simbólicas do ambiente. 


\section{Metodologia}

A metodologia nesta pesquisa foi baseada nas técnicas descritas no Roteiros de Experimentos de Química para Demonstração em sala de aula. Houve a montagem de vários experimentos de química tai como:

- Amoeba;

- Lâmpada de Lavra.

- Pasta de Elefante;

- Queimando o Real;

- Torre de Líquidos;

- Varinha Mágica;

Assim como foi possível contextualizar alguns equipamentos de física também, são eles:

- Diapasão;

- Gerador de Van de Graaff;

- $\quad$ Ilusão de ótica;

- Lâmpadas de catodo Frio;

- Mapeamento do Campo Magnético;

- Óculos de difração;

Os experimentos foram realizados em um stand disponibilizado pelos organizadores da feira, localizado em local estratégico de muita circulação de pessoas, para a execução das práticas uma bancada foi montada no local, permitindo assim que os expectadores pudessem interagir com a experimentação e presenciar as reações instantâneas, as práticas foram selecionadas sempre mantendo-se o cuidado de serem inofensivas, para que as mesmas não machucassem ninguém.

\section{Resultados e Discussões}

A proposta de levar a experimentação para uma feira agropecuária foi fruto de um dos objetivos do programa PDVL, que busca despertar vocações para as licenciaturas. A ideia central da proposta foi utilizar a experimentação para incentivar as pessoas a conhecerem o curso de Licenciatura em Química. Porém à medida que os experimentos iam sendo realizados, chamavam a atenção de todos que passavam no local e quando se aproximavam dos alunos que realizavam as experiências, podia-se perceber uma grande diversidade de pessoas que visitavam o espaço.

Essa diversidade variava de crianças que se fascinavam pelas cores, adolescentes que 
curiosamente iam ver o que estava acontecendo, adultos e universitários que queriam conhecer um pouco mais e pessoas idosas que passavam pelo local e ficavam curiosos com a movimentação e cores das práticas. Pode-se perceber pelas observações e do diálogo com as pessoas, que a grande maioria tem certo repulso pela química, a dificuldade e os paradigmas estão relacionados à parte dos cálculos, que estão presentes nos conteúdos da disciplina. Bem como a falta de contextualização e experimentação na sala de aula, contribui para os pré-conceitos que se criam ao se falar da ciência em questão.

Verificou-se uma euforia por partes das pessoas quando percebiam que a teoria era contextualizada pela experimentação, à medida que se explicava o que acontecia em cada experimento se indagava o que a pessoa podia perceber, e assim poderia observar se o processo de aprendizagem estava acontecendo. A medida que as pessoas conseguiam assimilar o que lhes era explicado, ficava nítida a curiosidade delas por outros assuntos e outros experimentos.

Foi possível apresentar ao publico em geral as diferentes formas de promover a aprendizagem (imagem 1) e mostrar que a química esta em seu cotidiano, bem como mostrar aos discente e docente uma nova metodologia, usando uma festa típica da região para promover a aprendizagem. Diversificar o ambiente de aprendizagem buscando novas metodologias é melhorar o elo entre conhecimento e aprendizagem bem como promover interação de uma diversidade de pessoas. Haja vista que há a necessidade que se pense em educação, como transformadora do ambiente onde se vive e como objeto de valorização da cultura local sempre promovendo o ensino aprendizagem.

Imagem 1: Realização das atividades pelos bolsistas. Fonte: Própria.

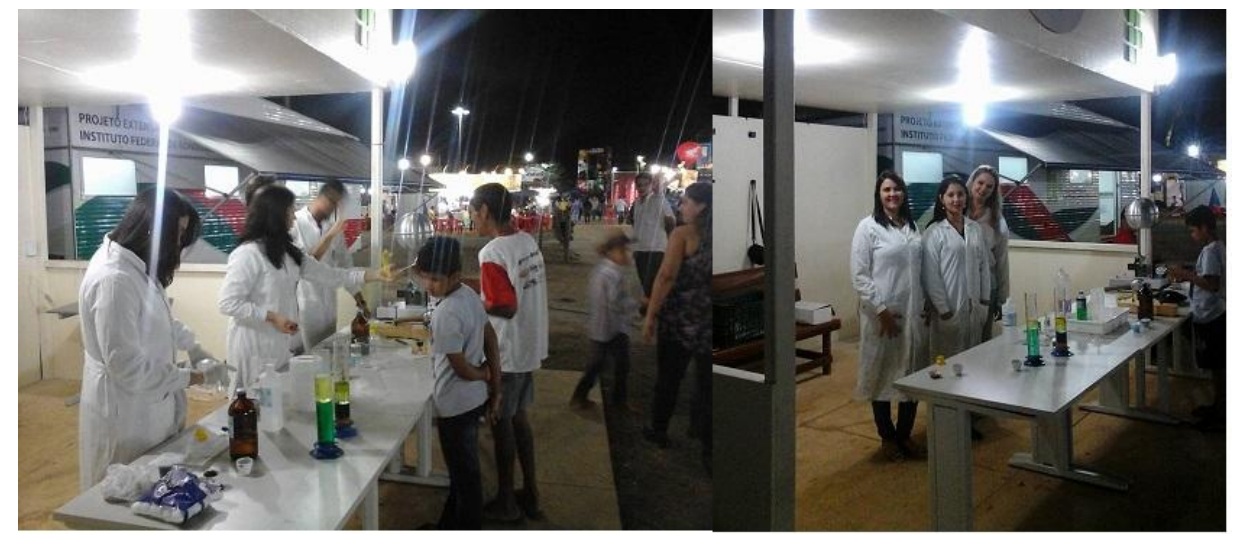

\section{Conclusões}

Conclui-se que proporcionar aos alunos diferentes ambientes de aprendizagem dentro da Química contribui significantemente para a criação de um elo entre conhecimento e prática, facilitando a mediação e transmissão das metodologias planejadas. Ao trabalhar a experimentação 
nesse contexto citado, aproxima-se o aluno e o conteúdo vinculado, envolvendo toda a comunidade no processo de aprendizagem. É importante trazer essa temática de análise experimental, pois assim criam-se facilidades em desenvolver no aluno o interesse pelos conteúdos, e aproximando e favorecendo o relacionamento entre as pessoas e toda a capacidade de desenvolvimento do aluno.

\section{Referências}

FORTE, C.M.S. Utilização de Dinâmicas de grupo na facilitação do processo de ensino e aprendizagem em química. In: SIMPOSIO DE EDUCAÇÃO EM QUÍMICA, 4, 2006, Fortaleza Disponível em: <http://www.abq.org.br/simpequi/2006/trabalhos/42-224-T1.htm> Acesso em 15 Out. 2015.

GUIMARÃES, C. C. Experimentação no Ensino da Química: Caminhos e Descaminhos Rumo à Aprendizagem Significativa. Química Nova na Escola. v. 33, n.3, p. 198.2009. Disponível em: <http://www.qnesc.sbq.org.br/online/qnesc31_3/> Acesso em 15 de Out. de 2015.

KRÜGER,Verno. A reprovação em Química na série inicial do $2^{\mathbf{0}}$ grau: uma análise dos fatores determinantes e contribuições para a solução dos problemas. Porto Alegre: UFRGS, 1990.

MOREIRA, Adelson F. Ambientes de Aprendizagem no Ensino de Ciência e Tecnologia. Belo Horizonte: CEFET-MG, 2007. Notas de aula.

MORIN, E. A cabeça bem feita: Repensar a Reforma, Reformar o Pensamento. $8^{a}$ ed. Rio de Janeiro: Bertrand Brasil, 2003. 128p.

RIBEIRO,L.;VANUCHI,C,F,V.;SOUZA,A,F.;BAPTISTA,A,A,J.;ZAN,A,R.Revista Criptoquímica: Produção e Aplicação de uma nova Ferramenta para o ensino de química. In XVII Encontro Nacional de Ensino de Química (XVII ENEQ). Ouro Preto, MG, Brasil ENEQ/2014. Caderno de Resumos. Ouro-Preto-MG: Sociedade Brasileira de Química, 2014. v. 1. p. 120-155, 2015

SILVA,C,S. Experimentação e contextualização no ensino de química: Pilhas.Universidade Federal de Goiás.Anapolis-GO,2014. 32 p. Dissertação (Ensino das Ciências). Unidade Universitária de Ciências Exatas e Tecnológicas Coordenação de Licenciatura em Química.2014.

VANUCHI,C,F,V.;SOUZA,A,F.;RIBEIRO,L.; BAPTISTA，A ,A,J.;ZAN,A,R.Quimolécula: kit Molecular com sementes Amazônica, uma nova proposta para o ensino de Química. In XVII Encontro Nacional de Ensino de Química (XVII ENEQ). Ouro Preto, MG, Brasil ENEQ/2014. Caderno de Resumos. Ouro-Preto-MG: Sociedade Brasileira de Química, 2014. v. 1. p. 33-150, 2015.

VEIGA,M,S,M.; QUENENHENN,A.; CARGNIN,C. O ENSINO DE QUÍMICA: algumas reflexões. I Jornada de didática - O ensino como foco, I fórum de professores de didática do estado do Paraná. ISBN 978-85-7846-145-4.2012.

VIANNA, F,J.(org.) Roteiros de Experimentos de Química para Demonstração em sala de aula. v.1,p-175.Dourados-MS Novembro/2013 